\title{
Thermodynamic and Interactions studies of $D(+)$ Fructose with aqueous alkali metals halides at different molalities and constant temperature
}

\author{
Yasmin Akhtar \\ Department of Chemistry, University of Tabuk, Tabuk, Saudi Arabia \\ Email address: \\ dryasminakhtar2004@yahoo.com
}

\section{To cite this article:}

Yasmin Akhtar. Thermodynamic and Interactions Studies of D(+) Fructose with Aqueous Alkali Metals Halides at Different Molalities and Constant Temperature. International Journal of Science, Technology and Society. Special Issue: Academic Research for Multidisciplinary. Vol. 3, No. 1-2, 2015, pp. 1-5. doi: 10.11648/j.ijsts.s.2015030102.11

\begin{abstract}
The present experimental investigation was carried out in order to explore the possible thermodynamic and interactions studies of $\mathrm{D}(+)$ fructose with mixed solvent of aqueous alkali metal halides at different molalities and constant temperature. Experimental values of densities and ultrasonic velocities were carried out of the ternary mixture solution $\mathrm{D}(+)$ fructose with aqueous $\mathrm{NaCl}, \mathrm{KCl}, \mathrm{MgCl}_{2}$ and $\mathrm{CaCl}_{2}$ under different molalities and at $303 \mathrm{~K}$. The related and relevant parameters correlated to the present study such as adiabatic compressibility $\mathrm{K}_{\mathrm{s}}$, acoustic impedance $\mathrm{Z}$, apparent molal volume $\phi_{\mathrm{v}}$, apparent molal adiabatic compressibility, $\phi \mathrm{K}_{\mathrm{s}}$ and partial molal volume $\phi^{0}{ }_{\mathrm{v}}$ and partial molal adiabatic compressibility, $\phi^{0} \mathrm{~K}_{\mathrm{s}}$ at infinite dilution. The present investigation has exploited the possible molecular associations such as ion-ion, ionsolvent, interactions in these systems. It has been observed that there exist strong solute-solvent interaction and complex formation between in these ternary systems.
\end{abstract}

Keywords: $\mathrm{D}(+)$ fructose, Aqueous Electrolytes, Apparent Molal Volume and Apparent Molal Adibatic Compresibility, Adiabatic Compressibility, Acoustic Impedance

\section{Introduction}

Carbohydrates are very important for some physiological process. They are not only basic material but also play significant role in the configuration of biological molecules. The study of thermodynamic properties of carbohydrates in aqueous and non-aqueous solvent is an important step for understanding their behavior biological fluids containing different ionic species. Also, it can provide useful information regarding conformational stability and interaction in the ternary system (1). Ultrasonic technique has been found to be more accurate and comprehensive in understanding solutesolvent interactions. To understand the role played by the biological molecules in living organism $(2 \& 3)$. There has been number of physicochemical studies of amino acids in aqueous carbohydrates solutions (4-6). Amino acids have zwitter-ion and are the constituents of the most important class of biopolymers, i.e. Proteins. Disarrangement water and electrolyte balance in living systems cause a wide variety of health problems. In physiological media such as blood, membranes, cellulose fluids etc., the dipolar character of amino acids (in presence of ions such as $\mathrm{Na}^{+}, \mathrm{K}^{+}, \mathrm{Mg}^{+2}$ and $\mathrm{Cl}^{-}$ etc., dissolved in body water) has an important bearing on their biological functions. Carbohydrates located at cell surfaces are important receptors for the bioactive structures of enzymes, hormones, viruses, antibodies etc. The electrolyte carbohydrates and protein - carbohydrates interactions are important for immunology, biosynthesis pharmacology, medicine and cosmetic industry. The complex conformational and configurationally factors determining the structure of carbohydrates in aqueous electrolytes solutions (7-9).

Recently, we have made systematic effort to investigate the ultrasonic properties of carbohydrates and amino acids in concentrated electrolytic solution $(10 \& 11)$. It was found that glucose interacts with aqueous electrolytes which indicate solute-solvent interactions are strong and complex formation in these ternary systems. The L-Proline and LGlutamine with aqueous $\mathrm{NaCl}$ and $\mathrm{MgCl}_{2}$ increase the apparent molar volume of these systems. This increase could be attributed to the interactions of the ions of the $\mathrm{NaCl}$, $\mathrm{MgCl}_{2}$ L-Proline and L- Glutamine electrolytes and zwitter- 
ion head group of amino acids, causing the transfer of hydrated water molecule to the bulk state.

In the present paper, we report densities, $\rho$ and ultrasonic velocities, $u$ of ternary systems of $\mathrm{D}(+)$ fructose with mixed solvent of aqueous $\mathrm{NaCl}, \mathrm{KCl}, \mathrm{MgCl}_{2}$ and $\mathrm{CaCl}_{2}$ have been determined experimentally at $303 \mathrm{~K}$. From these experimental data a number of thermodynamic parameters namely, the adiabatic compressibility $\mathrm{K}_{\mathrm{s}}$, acoustic impedance $Z$, apparent molal volume $\phi_{\mathrm{v}}$, apparent molal adiabatic compressibility, $\phi \mathrm{K}_{\mathrm{s}}$, and partial molal volume $\phi_{\mathrm{v}}^{0}$ and partial molal adiabatic compressibility, at infinite dilution respectively have been calculated. These parameters were utilized to study various interactions taking place in the solutions of these ternary systems were measured at $303 \mathrm{~K}$.

\section{Experimental}

\subsection{Chemicals and Preparation}

$\mathrm{D}(+)$ fructose $\left(99.5 \%\right.$ purity), $\mathrm{NaCl}, \mathrm{KCl}, \mathrm{MgCl}_{2}$ and $\mathrm{CaCl}_{2}$ (99.8\% purity) were procured from E Merck Germany and $\mathrm{S} d$ Fine Ltd. was used as such without further purifications, except drying in an oven for $24 \mathrm{hrs}$. The ultrasonic velocities and densities of the fructose in aqueous electrolytes solutions at various concentrations as well as in triple distilled de-ionized water were measured experimentally. The triple distilled water was used to make aqueous solvent of $\mathrm{NaCl}, \mathrm{KCl}, \mathrm{MgCl}_{2}$ and $\mathrm{CaCl}_{2}$ and these were used as solvent to prepared $\mathrm{D}(+)$ fructose solutions. All the solutions were stored in special air-tight bottles and kept in dark to avoid photo chemical degradation. The weighing was done on an electronic balance (model: GR-202R, and Japan) with a precision of $\pm 0.01 \mathrm{mg}$.

\subsection{Measurement of Density and Ultrasonic Velocity}

The densities were measured with a single capillary pycnometer (made of Borosil glass) of bulb capacity of $8 \times 10^{-}$ ${ }^{6} \mathrm{~m}^{3}$. The marks of the stems were calibrated using double distilled water at $303 \mathrm{~K}$. The pycnometer was kept for about 30 minutes in a thermostatic water bath so that the thermal fluctuation in density was minimized. The ultrasonic velocities in solutions were measured using a single crystal variable path interferometer at $3 \mathrm{MHz}$. The temperature of the test solutions was maintained at $303 \pm 0.02 \% \mathrm{~K}$ in an electronically controlled thermostatic water bath. The velocity and density data were found to be accurate with in \pm $0.10 \%$ and $\pm 0.01 \%$ respectively.

\section{Results and Discussion}

The densities and ultrasonic velocities of the $\mathrm{D}(+)$ fructose with mixed solvent of aqueous $\mathrm{NaCl}, \mathrm{KCl}, \mathrm{MgCl}_{2}$ and $\mathrm{CaCl}_{2}$ (0.068, 0.075, 0.084, 0.096, 0.112, 0.137, 0.179, m ) were determined at $303 \mathrm{~K}$ are recorded in Table 1 .The values of $\rho$ and $u$ increase and non-linearly with increase in concentration of all the ternary systems under investigation, which appear to be due to hydrophobic properties of solutes i.e. H-bond forming . Solutes may occupy the interstitial spaces in solvent or get solvated forming new weaker bonds. It was suggested (12) that what is experimentally observed for any systems reflect the compromise between the tendency for the ions and sugar to interact with each other and inclination of the solutes to associate with the solvent. The change in structure of solvent or solution as a result of $\mathrm{H}$ bond formation leads to decrease in intermolecular free length. The variation of ultrasonic velocity with the concentration of fructose, $(\mathrm{du} / \mathrm{dc})$ can be shown to depend upon the concentration derivations of the density and adiabatic compressibility of the system investigated.

Thus in the relation:

$$
\mathrm{du} / \mathrm{dc}=-\mathrm{u} / 2\left[1 / \rho(\mathrm{d} \rho / \mathrm{dc})+\left(1 / \mathrm{K}_{\mathrm{s}}\right)\left(\mathrm{d} \mathrm{K}_{\mathrm{s}} / \mathrm{dc}\right)\right]
$$

The quantity $(1 / \rho)(\mathrm{d} \rho / \mathrm{dc})$ is positive while $\left(1 / \mathrm{K}_{\mathrm{s}}\right)(\mathrm{d} \mathrm{K} / \mathrm{dc})$ is positive and the net value is negative. This makes $\mathrm{du} / \mathrm{dc}$ positive, showing that $\mathrm{u}$ increases with the concentration of the ternary systems which is in good agreement with the results reported for glycine and D-L alanine from water to aqueous sodium sulphate [13]

\subsection{Adiabatic Compressibility}

The adiabatic compressibility of the fructose + water + $\mathrm{NaCl}, \mathrm{KCl}, \mathrm{MgCl}_{2}$ and $\mathrm{CaCl}_{2}$ were determined at $303 \mathrm{~K}$ from the density and velocity data. The adiabatic compressibility was calculated by this relation

$$
\mathrm{K}_{\mathrm{s}}=1 / \mathrm{u}^{2} \rho
$$

The per usual of Table 2 exhibits the values of the adiabatic compressibility, $\mathrm{K}_{\mathrm{s}}$ is found to be decrease with the concentration of solute $(\mathrm{D}(+)$ fructose $)$ in all the ternary systems. Such a decrease in adiabatic compressibility observed in the ternary systems (fructose + water + electrolytes) clearly confirms the conclusion drawn from the ultrasonic velocity data. It is well known fact that when a solute dissolves in a solvent. Some of the solvent ions $\mathrm{Ca}^{+}$, $\mathrm{K}^{+}, \mathrm{Mg}^{+2}$ and $\mathrm{Ca}^{+2}$ ) are attach to the molecules of fructose because of solute-solvent interactions. Since the solvent molecules are oriented in ionic field (i.e. electrostatic field of ions $\left(-\mathrm{CH}_{2} \mathrm{OH}\right.$ and $\left.\mathrm{CHO}\right)$. The solvent molecules are more compactly packed in the primary salvation shells. This is the reason, why solvent is compressed by the introduction of the ions. Thus the electrostatic field of the ions causes the compression of the medium giving rise to phenomenon called 'Electrostriction'. Since the water molecules are compressed, they do not respond to a further application of pressure. So the solutions become harder to compress. This will lead to the decrease in compressibility values. This may further ascribed that such a decrease in adiabatic compressibility, $\mathrm{K}_{\mathrm{s}}$ is attributed to the influence of the electrostatic field of the ions $\left(\mathrm{Na}^{+}, \mathrm{K}^{+}, \mathrm{Mg}^{+2}\right.$ and $\left.\mathrm{Ca}^{+2}\right)$ on the accompanying molecules. It may be inferred that the weakening of hydrogen bond strength formed by the solute and solvent molecules and maximum complex formation may also be the reason for decrease in compressibility. Thus is in accordance with the 
view proposed by others [15 \&16].

\subsection{Acoustic Impedance}

The values of acoustic impedance, $\mathrm{Z}$ of these ternary systems (fructose + water + electrolytes) were calculated by the following relation and are reported in Table 1.

$$
\mathrm{Z}=\mathrm{u} \cdot \rho
$$

The values of $\mathrm{Z}$ increase with increases in molality of electrolytes which indicates solute-solvent interaction are strong and they behave as structure makers are shown in Table 1.The specific acoustic impedance of the medium for the particular type of wave being propagated and through it. The transmission of acoustic wave from one medium to another is important for transmission phenomenon in fluids. It may also correlated with ionic size $\mathrm{Na}^{+}, \mathrm{K}^{+}, \mathrm{Mg}^{+2}$ and $\mathrm{Ca}^{+2}$ of ions. A definite correlation the specific acoustic impedance and dielectric constant of the solvent medium. The behavior of acoustic impedance can be explained on the basis of lyophobic interaction between solute (fructose) and solvent ( aqueous $\mathrm{NaCl}, \mathrm{KCl}, \mathrm{MgCl}_{2}$ and $\mathrm{CaCl}_{2}$ ) molecules, which maximum complex ion formation and become responsible for the propagation of ultrasonic wave.

Table 1. Densities ( $\rho$ ) and ultrasonic velocity (u) of $D(+)$ fructose + aqueous $\mathrm{NaCl}, \mathrm{KCl}, \mathrm{MgCl}_{2}$ and $\mathrm{CaCl}_{2}$ solution at $303 \mathrm{~K}$

\begin{tabular}{|c|c|c|c|c|}
\hline $\begin{array}{l}\mathrm{m}(\mathrm{mol} \\
\left.\mathrm{Kg}^{-1}\right)\end{array}$ & $\rho\left(\mathrm{kg} \mathrm{m}^{-3}\right)$ & $\mathbf{u}\left(\mathrm{ms}^{-1}\right)$ & $K_{s}\left(10^{-10} \mathrm{~m}^{-2} \mathrm{~N}^{-1}\right)$ & $\mathrm{Z} 10^{6}\left(\mathrm{Kg} \mathrm{m}^{-2} \mathrm{~s}^{-1}\right)$ \\
\hline \multicolumn{5}{|c|}{$0.5 \mathrm{~m}$ fructose + water $+\mathrm{NaCl}$} \\
\hline 0.068 & 981.5 & 1505.2 & 4.497 & 1.477 \\
\hline 0.075 & 982.4 & 1506.4 & 4.496 & 1.480 \\
\hline 0.084 & 983.4 & 1508.2 & 4.471 & 1.483 \\
\hline 0.096 & 984.0 & 1508.9 & 4.463 & 1.485 \\
\hline 0.112 & 984.6 & 1510.4 & 4.461 & 1.487 \\
\hline 0.137 & 985.5 & 1511.6 & 4.441 & 1.489 \\
\hline 0.179 & 988.0 & 1513.4 & 4.420 & 1.495 \\
\hline \multicolumn{5}{|c|}{$0.5 \mathrm{~m}$ fructose + water $+\mathrm{KCl}$} \\
\hline 0.068 & 981.5 & 1505.4 & 4.495 & 1.478 \\
\hline 0.075 & 982.2 & 1506.5 & 4.486 & 1.480 \\
\hline 0.084 & 983.4 & 1507.2 & 4.478 & 1.482 \\
\hline 0.096 & 983.7 & 1508.0 & 4.472 & 1.483 \\
\hline 0.112 & 985.9 & 1509.1 & 4.444 & 1.488 \\
\hline 0.137 & 985.7 & 1512.0 & 4.438 & 1.490 \\
\hline 0.179 & 989.9 & 1513.0 & 4.413 & 1.498 \\
\hline \multicolumn{5}{|c|}{$0.5 \mathrm{~m}$ fructose + water $+\mathrm{CaCl}_{2}$} \\
\hline 0.068 & 987.3 & 1506.2 & 4.464 & 1.487 \\
\hline 0.075 & 988.7 & 1508.2 & 4.446 & 1.491 \\
\hline 0.084 & 989.4 & 1509.1 & 4.438 & 1.493 \\
\hline 0.096 & 992.4 & 1510.9 & 4.415 & 1.499 \\
\hline 0.112 & 992.9 & 1513.1 & 4.399 & 1.502 \\
\hline 0.137 & 993.0 & 1515.1 & 4.387 & 1.504 \\
\hline 0.179 & 993.4 & 1516.2 & 4.378 & 1.506 \\
\hline \multicolumn{5}{|c|}{$0.5 \mathrm{~m}$ fructose + water $+\mathrm{MgCl}_{2}$} \\
\hline 0.068 & 986.6 & 1506.2 & 4.468 & 1.486 \\
\hline 0.075 & 987.5 & 1507.3 & 4.456 & 1.488 \\
\hline 0.084 & 988.3 & 1508.3 & 4.448 & 1.491 \\
\hline 0.096 & 996.7 & 1509.4 & 4.403 & 1.504 \\
\hline 0.112 & 997.2 & 1511.5 & 4.389 & 1.498 \\
\hline 0.137 & 998.5 & 1514.7 & 4.365 & 1.507 \\
\hline 0.179 & 998.9 & 1516.4 & 4.355 & 1.515 \\
\hline
\end{tabular}

\subsection{Apparent Molal Volume}

Table 2. Apparent molal volume $\left(\phi_{v}\right)$ apparent molal adiabatic compressibility $\left(\phi_{\mathrm{Ks}}\right)$ of $\mathrm{D}(+)$ fructose + aqueous $\mathrm{NaCl}, \mathrm{KCl}, \mathrm{MgCl}_{2}$ and $\mathrm{CaCl}_{2}$ solution at $303 \mathrm{~K}$.

\begin{tabular}{|c|c|c|}
\hline $\mathrm{m}\left(\mathrm{mol} \mathrm{Kg}{ }^{-1}\right)$ & $\phi_{\mathrm{v}}\left(10^{-8} \mathrm{~m}^{3} \mathrm{~mol}^{-1}\right)$ & $-\phi_{K} S\left(10^{-8} \mathrm{~m}^{2} \mathrm{~N}^{-1} \mathrm{~mol}^{-1}\right)$ \\
\hline \multicolumn{3}{|c|}{$0.5 \mathrm{~m}$ fructose + water $+\mathrm{NaCl}$} \\
\hline 0.068 & 12.23 & 33.90 \\
\hline 0.075 & 14.38 & 39.90 \\
\hline 0.084 & 15.31 & 43.79 \\
\hline 0.096 & 16.75 & 42.44 \\
\hline 0.112 & 18.78 & 40.31 \\
\hline 0.137 & 20.35 & 50.47 \\
\hline 0.179 & 22.24 & 80.29 \\
\hline \multicolumn{3}{|c|}{$0.5 \mathrm{~m}$ fructose + water $+\mathrm{KCl}$} \\
\hline 0.068 & 11.21 & 38.45 \\
\hline 0.075 & 13.57 & 42.90 \\
\hline 0.084 & 16.91 & 43.09 \\
\hline 0.096 & 18.50 & 46.38 \\
\hline 0.112 & 20.01 & 38.40 \\
\hline 0.137 & 21.92 & 58.39 \\
\hline 0.179 & 22.05 & 78.38 \\
\hline \multicolumn{3}{|c|}{$0.5 \mathrm{~m}$ fructose + water $+\mathrm{CaCl}_{2}$} \\
\hline 0.068 & 16.75 & 70.54 \\
\hline 0.075 & 17.48 & 72.91 \\
\hline 0.084 & 18.75 & 74.40 \\
\hline 0.096 & 19.76 & 111.33 \\
\hline 0.112 & 21.01 & 113.00 \\
\hline 0.137 & 22.10 & 104.62 \\
\hline 0.179 & 23.01 & 93.12 \\
\hline \multicolumn{3}{|c|}{$0.5 \mathrm{~m}$ fructose + water $+\mathrm{MgCl}_{2}$} \\
\hline 0.068 & 23.30 & 85.80 \\
\hline 0.075 & 24.25 & 91.50 \\
\hline 0.084 & 25.5 & 90.91 \\
\hline 0.096 & 26.91 & 88.71 \\
\hline 0.112 & 27.85 & 96.00 \\
\hline 0.137 & 28.01 & 145.07 \\
\hline 0.179 & 28.20 & 143.01 \\
\hline
\end{tabular}

The apparent molal volume, $\phi_{\mathrm{v}}$ were calculated from measured density data of fructose in aqueous metal halides namely $\mathrm{NaCl}, \mathrm{KCl}, \mathrm{MgCl}_{2}$ and $\mathrm{CaCl}_{2}$ solution at different molality and at $303 \mathrm{~K}$ using the following equation:

$$
\phi_{\mathrm{v}}=\left[1000\left(\rho^{0}-\rho\right) / m \rho \rho^{0}\right]+M / \rho
$$

Where $M$ is the molecular mass of the solute, $\rho^{0}$ and $\rho$ are densities of solvent and solution. The calculated values of $\phi_{\mathrm{v}}$ of these ternary systems are given in Table 2 . In these cases where molality dependence of $\phi_{\mathrm{v}}$, having definite trend points. The $\phi_{\mathrm{v}}$ values increase due to reduction in the electrostriction effect at terminals, whereas it decreases due to disruption of side group hydration by that of the charged end.

The partial molal volume at infinite dilution $\phi^{\circ}{ }_{\mathrm{v}}$ was calculated by taking an average data points. The linear variation is obtained by least square fitting to the following equation.

$$
\Phi_{\mathrm{v}}=\phi_{\mathrm{v}}^{0}+\mathrm{S}_{\mathrm{v}} \mathrm{m}^{1 / 2}
$$

The intercept which is the limiting apparent molal volume at infinite dilution $\phi^{0}{ }_{\mathrm{v}}$ is the experimental slope, $\mathrm{S}_{\mathrm{v}}$ which is considered to be volumetric pair wise coefficient. The 
derived values $\phi^{0}{ }_{\mathrm{v}}$ of along with $\mathrm{S}_{\mathrm{v}}$ are summarized in Table 3. The values of $\phi^{0}{ }_{\mathrm{v}}$ are positive of these ternary systems which indicate ion-solvent interactions are strong. The values of $\phi^{0}{ }_{\mathrm{v}}$ are less in presence in presence of metal ions $\left(\mathrm{Na}^{+}\right.$and $\mathrm{K}^{+}$) than those of divalent ions $\left(\mathrm{Ca}^{+2}\right.$ and $\left.\mathrm{Mg}^{+2}\right)$. A mutual comparison of these electrolytes shows the values of $\phi^{0}{ }_{\mathrm{v}}$ are larger in case of $\mathrm{Ca}^{+2}$ and $\mathrm{Mg}^{+2}$ than in $\mathrm{Na}^{+}$and $\mathrm{K}^{+}$. The $\mathrm{Ca}^{+2}$ and $\mathrm{Mg}^{+2}$ ions are being smaller in size, has an intense force field and hence strong hydration co-sphere around them therefore, hydration of $\mathrm{MgCl}_{2}$ and $\mathrm{CaCl}_{2}$ ( Solute - solvent interaction) will be much more than that of $\mathrm{NaCl}$ and $\mathrm{KCl}$.

\subsection{Apparent Molal Adiabatic Compressibility}

The density and adiabatic compressibility values were employed for calculated apparent molal adiabatic compressibility, $\phi \mathrm{K}_{\mathrm{s}}$ of fructose in aqueous metal halides namely $\mathrm{NaCl}, \mathrm{KCl}, \mathrm{MgCl}_{2}$ and $\mathrm{CaCl}_{2}$ solution at different molality and at $303 \mathrm{~K}$ using the equation

$$
\phi K_{\mathrm{s}}=\left[1000\left(\rho_{\mathrm{Ks}}^{0}-\rho_{\mathrm{Ks}}{ }^{0}\right) / \mathrm{C} \rho \rho^{0}\right]+\mathrm{M}_{\mathrm{Ks}} / \rho
$$

Table 3 shows that the less negative values of $\phi \mathrm{K}_{\mathrm{s}}$ over the entire range of molality of the ternary systems which indicates strong solute-solvent interactions. The less negative values of $\phi \mathrm{K}_{\mathrm{s}}$ are due to loss of structural compressibility of solvent on increase in the population of four bonded solvent molecule in the vicinity of the solute molecules.

The partial molal adiabatic compressibility, $\phi^{\circ} \mathrm{K}_{\mathrm{s}}$ at infinite dilution are obtained from the plot of $\phi \mathrm{K}_{\mathrm{s}}$ versus $\mathrm{m}^{1 / 2}$ by least square method. The molality dependence of this parameter has been expressed in terms of the following equation

$$
\Phi_{\mathrm{Ks}}=\phi_{\mathrm{Ks}}^{0}+\mathrm{S}_{\mathrm{Ks}} \mathrm{m}^{1 / 2}
$$

Where $\phi_{\mathrm{Ks}}^{0}$ is the partial molal adiabatic compressibility at infinite dilution. It provides information regarding solutesolvent interaction. $\mathrm{S}_{\mathrm{Ks}}$ is the experimental slope. The values of $\phi_{\mathrm{Ks}}^{0}$ and $\mathrm{S}_{\mathrm{Ks}}$ are also included in Table 3 . The magnitude of negative values of $\phi_{\mathrm{Ks}}^{0}$ are higher in $\mathrm{MgCl}_{2}$ and $\mathrm{CaCl}_{2}$ systems suggesting that the presence of strong solute-solvent. The $\mathrm{Ca}^{+2}$ and $\mathrm{Mg}^{+2}$ ions are being smaller in size, has an intense force field and hence strong hydration co sphere around them and maximum complex ion formation. The hydration of $\mathrm{MgCl}_{2}$ and $\mathrm{CaCl}_{2}$ ( Solute - solvent interaction) will be much more than that of $\mathrm{NaCl}$ and $\mathrm{KCl}$. The values of $\mathrm{S}_{\mathrm{Ks}}$ fructose + water+ electrolytes are positive which is indicating the presence of strong ion-pair interactions. From this tabulation, one can notice that the values of in mixed ternary system less than the pure system suggesting the weak interactions in the ternary system by others[16].

Table 3. Partial molal volume $\left(\phi^{o}{ }_{v}\right)$ Partial molal adiabatic compressibility $\left(\phi_{K s}^{0}\right)$ and its experimental slope, $\left(S_{v}\right)$ and $\left(S_{K s}\right)$, of $D(+)$ fructose + aqueous

\begin{tabular}{|c|c|c|c|c|}
\hline $\mathrm{m}\left(\mathrm{mol} . \mathrm{Kg}^{-1}\right)$ & $\phi_{\mathrm{v}}^{0}\left(10^{-8} \mathrm{~m}^{3} \mathrm{~mol}^{-1}\right)$ & $S_{\mathrm{v}}\left(10^{-8} \mathrm{~m}^{3} \mathrm{~mol}^{-3 / 2} \mathrm{l}^{-1 / 2}\right)$ & $-\phi_{\mathrm{Ks}}^{0}\left(10^{-8} \mathrm{~m}^{5} \mathrm{~N}^{-1} \mathrm{~mol}^{-1}\right)$ & $-\mathrm{S}_{\mathrm{Ks}}\left(10^{-8} \mathrm{~m}^{5} \mathrm{~N}^{-1} \mathrm{~mol}^{-3 / 2} \mathrm{I}^{-1 / 2}\right)$ \\
\hline \multicolumn{5}{|c|}{ fructose + water $+\mathrm{NaCl}$} \\
\hline 0.5 & 25.38 & 63.70 & 7.02 & 4.280 \\
\hline \multicolumn{5}{|c|}{ fructose + water $+\mathrm{KCl}$} \\
\hline $\begin{array}{l}0.5 \\
\text { fructose }+ \text { wa }\end{array}$ & 27.38 & 60.01 & 6.73 & 6.919 \\
\hline $\begin{array}{l}0.5 \\
\text { fructose + wa }\end{array}$ & 28.40 & 79.02 & 8.02 & 10.86 \\
\hline 0.5 & 28.80 & 73.01 & 9.01 & 14.98 \\
\hline
\end{tabular}
$\mathrm{NaCl}, \mathrm{KCl}, \mathrm{MgCl}_{2}$ and $\mathrm{CaCl}_{2}$ solution at $303 \mathrm{~K}$

\section{Acknowledgement}

I am highly thankful to supervisor Mrs. Dr. Nadia Hussain , and Dr. T. Ahmad, Department of Chemistry, University of Tabuk, K.S.A for their co-operation and valuable suggestions.

\section{References}

[1] Y. Akhtar, J. international acad. Res. Multi Disipliry. , "Molecular and thermodynamic interaction of $\mathrm{D}(+)$ glucose with mixed solvent of electrolytes solutions at $303 \mathrm{~K}$ ", vol. 2 2014 pp 693-700.

[2] Y. Akhtar, S. F. Ibrahim, Arabian, "Ultrasonic and thermodynamic studies of glycine in aqueous electrolytes solutions at 303 K”, J. Arabian Chem. Vol. 42011 pp 487- 490.

[3] F. J. Millero, A. L. Surdo and C. Shiv, "Apparent molal volumes and adiabatic compressiblities of aqueous transition metals.” J. Phys. Com. Vol. 841980 pp 719-723.
[4] S. S. Aswale, S.R. Aswalev and and R. S. Hajare, "Adiabatic compressibility intermolecular free length and acoustic relaxation time of aqueous antibiotic cefotaxime sodium" Indian J. Chem., vol.4 2012 pp2671-2677.

[5] S. Thirumaran and J. K. Sabu, "Ultrasonic studies of interactions of some alkali halides in aqueous d-glucose solutions at varying molalities and temperature", Journal Exp. Sci., Vol. 32012 pp 33-39.

[6] M. J. Iqbal and M. A. Chaudhry, "Volumetric and viscometric studies of drugs in aqueous medium at different temperature", J. Chem. Engg. Vol. 542009 pp 2772-2776.

[7] A. K. Nain and R. Pal. " Study of solute- solute and solute solvent interacttions of Threonine in aqueous glucose solutions at different temperatures by using volumetric ans viscometric methods", J. Chem Thermodyn. , vol.104 2013; pp 60-98.

[8] E. J Gonzalez, S. B. Bottini, S. Peeda and E. A. Macedo, "Liquid- Liquid equlibria of binary systems, Experimental data and Thermodynamic modeling using a group contribution equation of state" Fluid Phase Equil. Vol.362 2014 pp163-169. 
[9] M. J. Iqbal and M. Siddiquah, " Partial molar volume of mefenamic acid in alcohol at temperature 293.15 and 313.15 K,”J. Braz. Chem. Soc. Vol.17 2006 pp727-735.

[10] F. Ciotta, J. P. M. Truster and V. Vesovic, “ Extended hard sphere model for the viscosity”, Fluid Phase Equilib. Vol.363 2014 pp 239-247.

[11] Y. Akhtar, "Volumetric and viscometric behavior of amino acids in aqueous metal electrolytes solutions at $308 \mathrm{~K}$ ", Fluid Phase Equil. Vol. 2582007 pp125-131.

[12] X. Jiang, C. Zhu and Y. Ma. "Volumetric and viscometric studies of amino acids in L-L-ascorbic acid aqueous solutions at temperature 293.15- $323.15 \mathrm{~K}$ ", J. Chem. Thermodyn. Vol.71 2014 pp 50-63.

[13] R. K. Wadi and P. Ramasmi "Partial molal volumes and adiabatic compessiblities of transfer of glycine and D-L alanine from water to aqueous sodium sulphate at 288.15, 298.15 and 308.15 K", J. Chem. Soc. Faraday Trans. Vol. 93 1997 243-247.

[14] M. S. Hussain, T. K. Biswas, D. C. Kabiraz, M. N. Islam and M. E. Haque, "Studies on sodium dodecylsulphate in aqueous and in aqueous amino acids solutions", J. Chem. Thermodyn. Vol.71 2014; pp 6-13.

[15] I.L. Shulgin and E. Ruckenstein "Relationship between preferential interac- tion of a protein in an aqueous mixed solvent and its solubility", Biophys Chem. Vol. 1182005 pp 128-34.

[16] Vishnu D., Y. Akhtar, J. D.Pandey, "Ultrasonic and Thermodynamic studies of Ternary solutions", Acta Acoust. , Vol 841998 pp 976981. 